\title{
UCLan reaches ten-year milestone in dentistry training
}

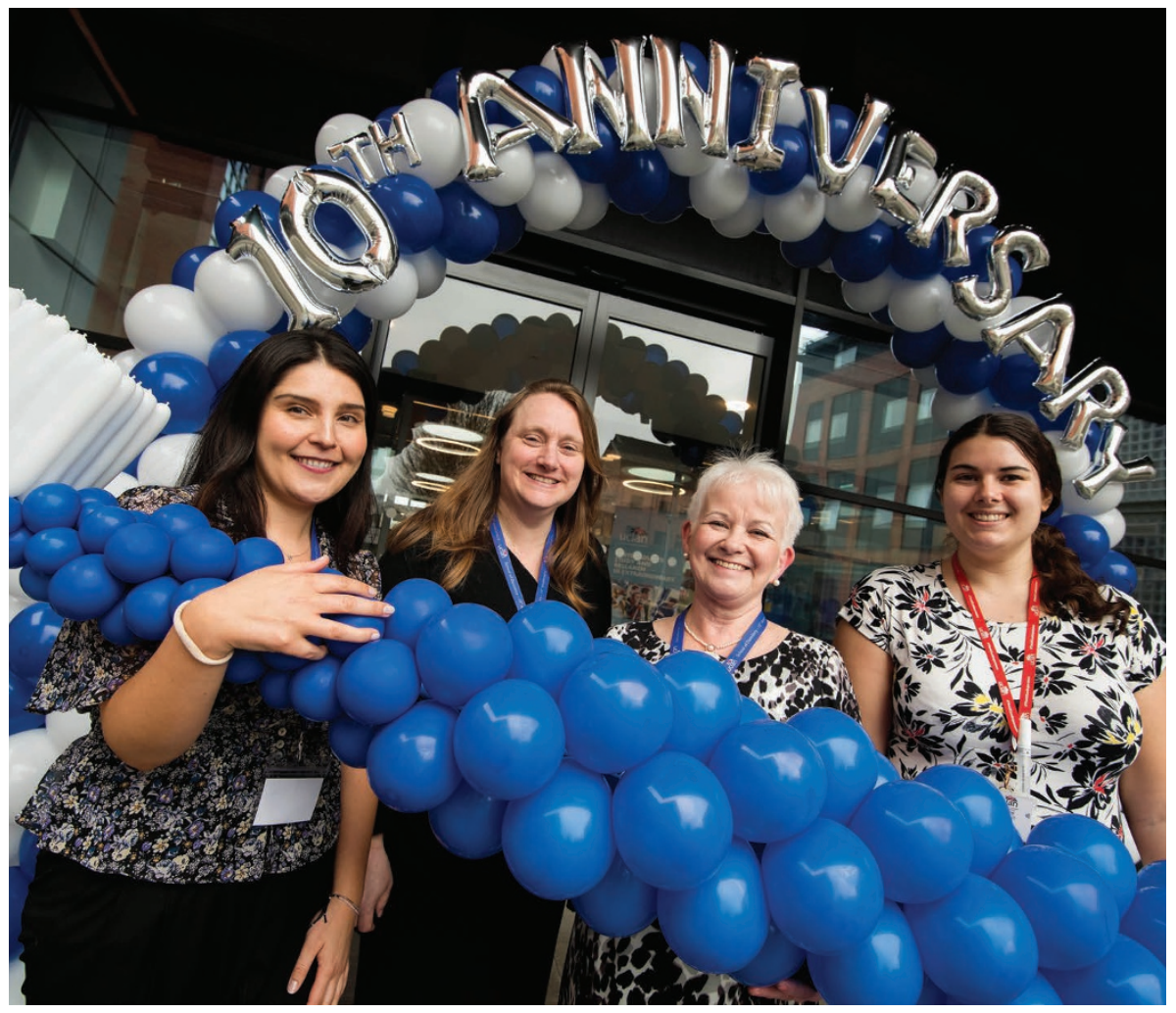

(I-r) Graduate Daniela Vargas, graduate Wendy Thompson, Angela Magee, Head of the UCLan School of Dentistry, and current 4th year graduate entry Bachelor of Dental Surgery (BDS) student Elie Martin

The University of Central Lancashire (UCLan) is celebrating a decade of training the next generation of dentists.

When UCLan's School of Dentistry opened its doors ten years ago, it was one of only two new dental schools to be created in England for over 100 years. Since then, UCLan dental students have treated more than 23,000 patients during their training and the school has produced 224 new dentists who have expanded the region's dental workforce considerably. Almost 60 of its new dental graduates have chosen to establish their careers in the Preston area with more settling in the wider North West region.

The University invested $£ 5.25$ million in its state-of the-art dental school in Preston, which has one of the most sophisticated 'phantom head' rooms in Europe. It is also one of the few universities in the country to boast its own on-campus dental clinic, allowing undergraduate students to obtain practical experience in high-end dental work.

The School was the first to pioneer a new mode of dental education, in which the graduate entry Bachelor of Dental Surgery students gain their experience in local community Dental Education Centres (DECs) rather than city centre hospitals, which has provided a good alternative to the traditional approach. The DECs, located in Accrington, Blackpool, Carlisle and Morecambe Bay, were established in areas of high need and poor dental health where access to NHS dentistry was limited, in part, owing to difficulties in attracting qualified dentists to the area.

At a special 10th anniversary event, which welcomed graduates and former staff back to the School, NHS England's Deputy Chief Dental Officer and UCLan Honorary Professor Eric Rooney commented: 'Over the last ten years many of the initial aims of the School have been fulfilled, helping patients and creating a vibrant dental academic community. Our population, their needs, and the way we care for them is changing and UCLan is well placed to develop and adapt over the next ten years and beyond.'
DENTISTS ON FILM

The Monuments Men

H. S. Brand of the Academic Centre for Dentistry Amsterdam, and movie buff, continues his new series of columns on films featuring dentists with The Monuments Men, an historical drama based on a true story, directed by George Clooney (2014).

During the Second World War, a team of museum directors and art historians helps the US Army to retrieve art stolen by the Nazis. While eating homemade jerky, one of the team members hurts a tooth. Together with a colleague he enters a shop with a sign in the shape of a tooth on the outside. It turns out that the dental surgery is a back room of a butcher's shop. While the dentist inspects the painful tooth he asks: 'So you're artists, huh?' The colleague of the patient explains they are collectors from New York and the patient is an architect. The dentist says that his nephew, who studied art in Paris, lives a few miles away and might be able to help the Americans. After the dentist has removed the offending tooth using a regular hammer, he accompanies the Americans in a Jeep to visit his nephew. The nephew lives in a cabin in the woods, full of paintings from Cézanne and Renoir. It turns out that the nephew was a Nazi officer, responsible for stealing trainloads of art from Paris. The Americans arrest the nephew, leaving the astonished dentist behind.

\section{BDA Branch AGM Notices}

The Annual General Meeting

of the East Lancashire and East Cheshire BDA

Branch will take place

at 18:30 on Wednesday

23 May at the Blue Tiffin Restaurant,

Oldham. To confirm your attendance or submit apologies please contact

branchsectionevents@bda.org. 